\title{
An Investigation on the Ultimate Strength of Cold-Formed Steel Bolted Connections
}

\author{
Nirut Konkong \\ Department of Civil Engineering \\ Faculty of Engineering \\ Kasetsart University \\ Bangkok 10900, Thailand \\ nirut.k@ku.th
}

\begin{abstract}
This paper presents experimental results and finite element analysis of the cold-formed steel bolted connection under shear loading. Experiments are conducted to study the ultimate behaviors, such as ultimate strength and failure mode of connections. The samples were fabricated into three different groups, single bolted, double bolted and quadruple bolted connection. Material properties were determined by tensile coupon testing. Bearing failure modes were detected in the bolted connection tests. The ultimate capacities were compared with the nominal strengths calculated using the AISI (2012). The comparisons show that the nominal strength parameters predicted by this specification is conservative. The finite element analysis shell elements were used to model the cold-formed steel plate while solid elements were used to model the bolted fastenings for the purpose of studying the structural behavior of bolted connections. Material nonlinearities, contact problem and geometry nonlinearities analysis are carried out in order to predict ultimate strength and failure mode of connections. The results show that the proposed model accurately represents the failure mode and ultimate strength of bolted connection, as determined from experimental investigation. The new factor for type of bearing connection has a good agreement with the tested bearing strength of bolt connection.
\end{abstract}

Keywords-cold-formed steel; bolted connections; finite element analysis; bearing mode; AISI (2012)

\section{INTRODUCTION}

Fastened joints are critical components in cold-formed steel structures. The member in the jointed components and stress concentration around the hole are very complex to design. Practical design of cold-formed steel connections are designed as pinned. The pinned connection is intended to transfer shear forces but cannot resist bending moment. Bolted connection is common in steel construction which can be used with both hotrolled and cold-formed steel. The structural behavior of bolted connections in cold-formed steel structure is quite different from hot-rolled steel, mainly because of the thickness of the connected parts. The load capacity of the connection is controlled by one of several failure modes including the shear failure of the plate, the bearing failure of the plate, the rupture in the net section and the shear failure of the bolts. Predicting failure mode in cold-formed steel connection is a complicated task, requiring knowledge of stress distribution in the connection and understanding of different failure mode with different loading configurations. It is very difficult to model the complicated failure mechanism by analytical methods. Thus, The Finite Element Analysis (FEA) can be used to predict the failure behavior of cold-formed steel structure. Numerical investigation based on the nonlinear finite element method is more effective method to analyze cold-formed steel behavior. In general, the methods available to consider the behavior of cold-formed sections include experiment investigation, analytical method based on the governing differential equations, finite-element method, and finite strip method. The finite element method is mostly used because of time efficiency compared to other methods [1]. The design standards of coldformed steel bolted connections available in the current practical design include, the American Iron and Steel Institute [2], Australian/New Zealand Standard [3] and Eurocode 3 Part 1-4 [4]. All design standards were modified from design standards of hot-rolled steel with modifications as experimental works.

In [5-10], authors compared the ultimate strength from test results with the design standards. The results showed that the design standards cannot accurately predict the load capacity for cold-formed steel bolt connections. Moreover, in [11], it was found that the AISI-S100 [12] accurately predicted for thick plate connections, but provided lower prediction accuracy for thin material. The main objective for this paper is to investigate the behavior and the strength of cold-formed steel bolted connections through experiments and FEA. The experimental investigation is performed by the shear testing of concentrically loaded bolted connections fabricated from G550 cold-formed steels. Experimental results of shear connections are compared with FEA and AISI-S100 [12] design standard. Finally, a new approach modification factor for type of bearing connection is proposed for modifying the AISI-S100 [12] bearing strength design equation.

\section{COLD FORMED STEEL BOLTED FAILURE MODES}

The failure mode of single shear bolted connections are classified in four modes, i.e., shearing of cold-formed steel (Shearing mode), bearing of material in front of the bolt 
(Bearing mode), tearing of the cold-formed steel in the net section (Net section mode) and shearing of the bolt (Bolt shear failure mode). In many cases, the connection is subjected to a combination of different types of failure modes as in Figure 1.

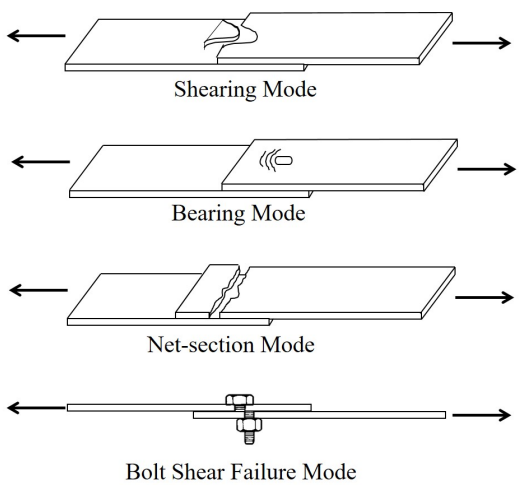

Fig. 1. Typical failures of single shear bolted cold-formed connections.

The definition of single shear and double shear connection refers to how a bolt is loaded when the force is perpendicular to the axis of the bolt. The single shear connection is a single plane of shear force through the bolt. The double shear connection is two shear planes through the bolt, the shear force is split into two locations on the bolt.

\section{COLD-FORMED STEEL}

The steel materials in this research were produced using a cold reduction process, which results in the increase in strength, hardness and the decrease of weight. The laboratory tests were performed using the G550 cold-formed steel with plate thickness of 1.0 millimeter for bolted connection test. For this research, G550 cold-formed steel with a plate thickness of 1.0 millimeter was called G550-1T. G550 is a hot-dipped zinccoated structural steel and minimum yield strength of $550 \mathrm{MPa}$. The section of cold-formed steel is shown in Figure 2 that is a lipped channel section. Material property requirements for G550 steels are specified by following ASTM Standards A370-07[13].

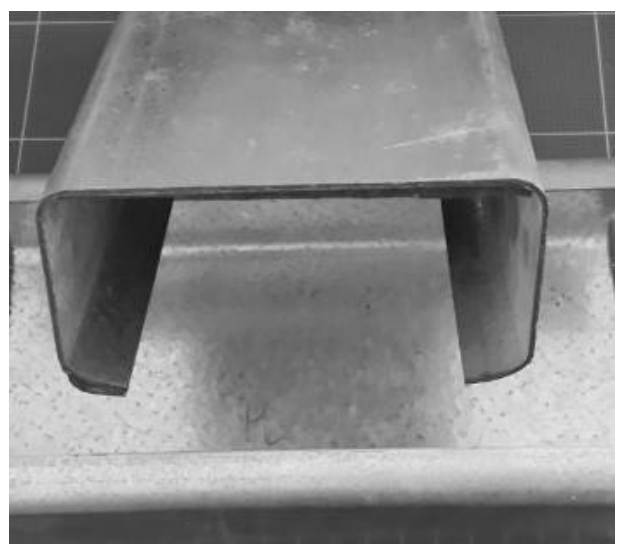

Fig. 2. Chanel with lip section using G550 cold-formed steel grade.

\section{MATERIAL PROPERTIES}

The material properties, i.e. the yield strength and ultimate strength of the cold-formed steel were obtained through the tensile testing of coated coupons according to ASTM A37007[13]. The bolt was confirmed by ASTM A325 [14]. The yield strength values for the cold-formed steel and bolt were calculated using the $0.2 \%$ proof stress method.

\section{BOLTED CONNECTION SPECIMENS}

The specimens of the shear connection were tested with various sizes and shapes, as well as different number of bolts. The bolt configuration include single bolt, double bolts and quadruple bolts arrangement. The specimens were cut from the web element of cold-formed lipped channel sections (C-102 x $51 \times 12.5 \times 1.0)$. Test specimens have three different configurations with various bolts number and bolt arrangement as shown in Figure 3. The possibility of bolting shear failure was eliminated by using M5 Grade 8.8 bolt conforming to ASTM A325M. The bolt diameter is 5 millimeters which was used on all tested configuration of connections. The size of oversize hole refers to the dimension specified in Table I. Bolts and nuts were assembled with integral washers that were tightened by hand, which allowed for slip of the connection after initial loading.

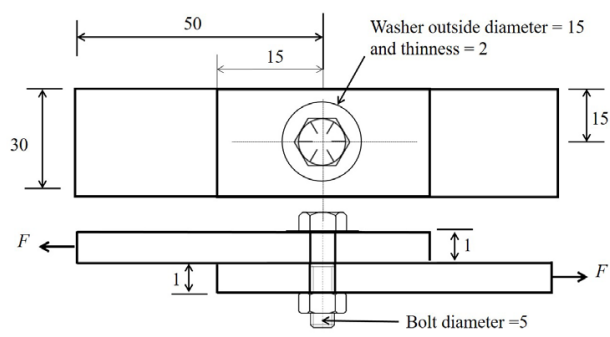

(a) Single-bolt connection

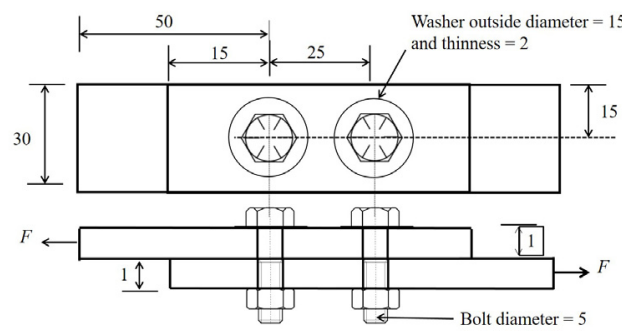

(b) Double-bolt connection

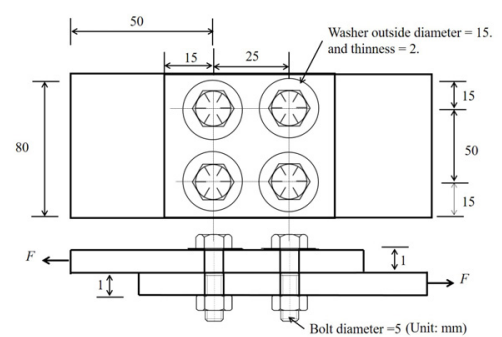

(c)Quadruple-bolt connection (Unit: $\mathrm{mm}$ )

Fig. 3. The configuration of tension bolted connection. 
TABLE I. DIMENSIONS OF OVERSIZE HOLES

\begin{tabular}{|c|c|}
\hline $\begin{array}{c}\text { Nominal bolt diameter } \\
d(\mathbf{m m})\end{array}$ & $\begin{array}{c}\text { Oversized holes diameter } \\
d_{h}(\mathbf{m m})\end{array}$ \\
\hline$<12.7$ & $d+0.8$ \\
\hline$\geq 12.7$ & $d+1.6$ \\
\hline
\end{tabular}

\section{SPECIMEN LABELLING}

The specimens are mainly divided into three groups according to the connection types, namely the single bolt shear, double bolts shear and quadruple bolts shear connections. All groups of connection contain configurations based on the number of bolt. The specimen is normally labelled by two parameters in order to identify the connection type and the number of bolt. The examples of the labelling are S-1, D-1 and Q-5. The first letter indicates the connection type; where $\mathrm{S}=$ single bolted connection, $\mathrm{D}=$ double bolted connection and $\mathrm{Q}=$ quadruple bolted connection. The second letter specifies the repeated test.

\section{EXPERIMENTAL METHOD}

The tests were completed using a universal testing machine (UTM) in the structural laboratory of Kasetsart University, Bangkok, Thailand. The load and the axial deformation were measured to capture the connection behavior. A typical bolted shear connection test setup is shown in Figure 4.

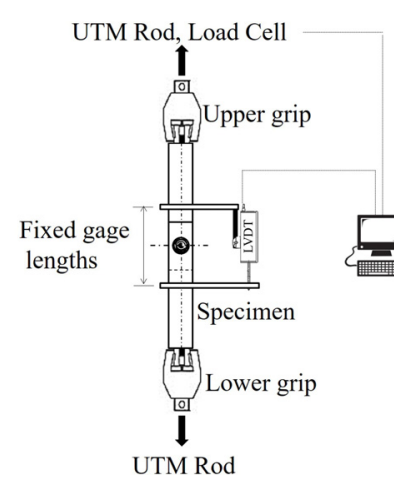

(a)

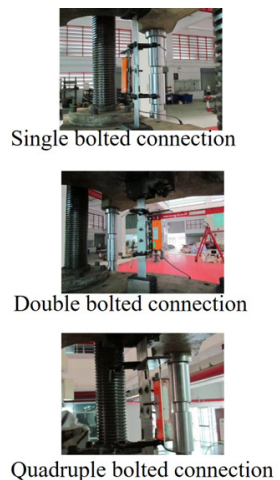

(b)
Fig. 4. Bolted connection test setup: (a) Schematic views of coldformed steel bolted connection test (b) Single bolted connection, double bolted connection and quadruple bolted connection.

The load was applied to the specimen using a displacement control. The expected loading speed to the specimens is displacement controlled with the speed of $1 \mathrm{~mm} /$ minute. The loading speed was therefore increased from the gradually growing deformations. The displacement of loading was measured by a Linear Variable Differential Transformer (LVDT). LVDT was setup to measure the elongation of single bolted, double bolted and quadruple bolted connection over a distance of 15,25 and 25 centimeters from the center line, respectively. All transducers were connected to a data logger with computer monitoring. Measuring data were observed at every 1.0 second interval and the data were transferred and stored in the computer hard disk. The failure of the specimen was described as the point at which the specimen entered plastic deformation. Once the applied load began to drop, even though the specimen continued to elongate, the test was stopped.

\section{FINITE ELEMENT MODELING AND VALIDATION}

The FEA on the cold-formed steel members is considered to be particularly useful in investigating the behavior of coldformed steel structures. Furthermore, the FEA can also provide essential information of the complex local behavior of the connections, such as the deformation shapes, structural stiffness, and stress distributions. The FEA was then performed using the ANSYS software package to simulate behavior of connection under shear loading. The FEA included three sources of nonlinearities including material, contact and geometric nonlinearities. The dimensions, material properties, and boundary conditions from the test were used in developing the geometry models as shown in Figure 5 (a).

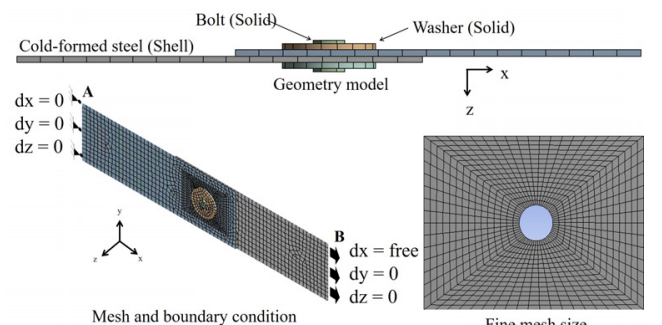

Geometry and mesh

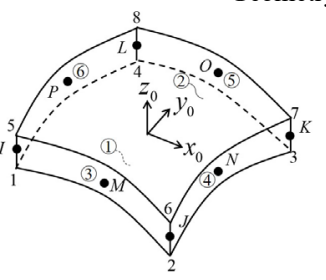

SHELL281

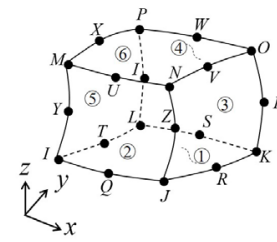

SOLID186

Shell and solid element
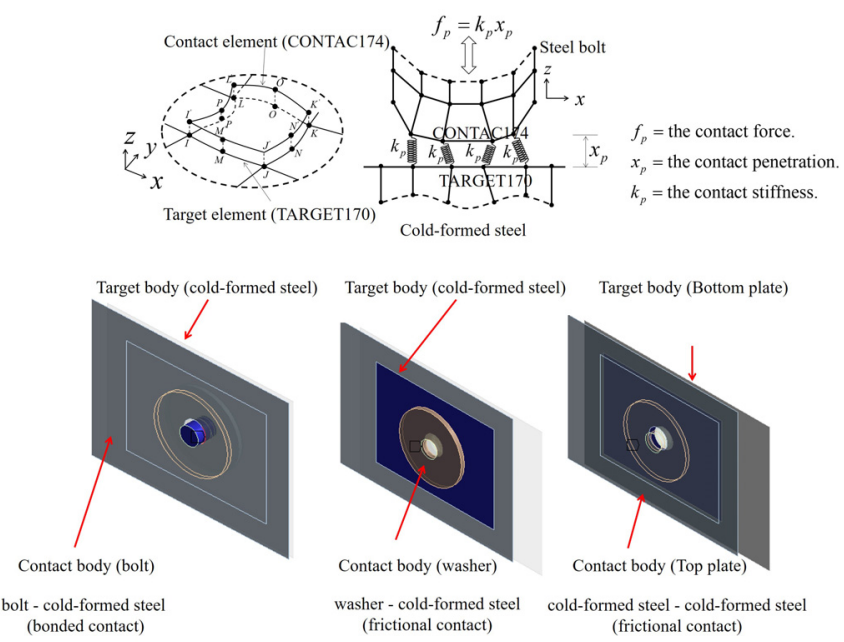

Fig. 5. Geometry model and contact types of finite element model 
A typical mesh is shown in Figure 5(b) for the modeling of the cold-formed steel the 8-node SHELL281 element with 6 DOFs was used. The steel bolts and washers were modeled using the SOLID186 3-D 20-node. The element between bolt and cold-formed steel was modeled using the node-to-surface 3-D CONTAC174 and TARGET170 as shown in Figure 5(c), which implement a pure penalty algorithm [15]. Mesh sizes were also chosen based on the appropriate aspect ratios (lengthto-width ratio). The element aspect ratios were selected to be closed to 1.0 for both cold-formed steel and bolt elements. Finer mesh was implemented around the holes for transferring the stress from the bolt to the cold-formed steel. In the experimental test, the specimens were pinched to the load transfer grips. The nodes along the end plates shown in Figure 5a were restrained with geometric boundary conditions as pinned and roller support. The line load was applied through nodes of the end plate along point $\mathrm{B}$. In this model, loading to finite element model was applied with the displacement control. The effect of friction coefficient was included, and a constant of friction coefficient of 0.18 was applied. The material properties of the specimens from the coupon testing were converted to the true stress $\left(\sigma_{\text {true }}\right)$ and true strain $\left(\varepsilon_{\text {true }}\right)$ using a multilinear isotropic hardening material model. It was converted by using (1):

$$
\sigma_{\text {true }}=\sigma_{\text {test }}\left(1+\varepsilon_{\text {test }}\right) \quad \text { and } \quad \varepsilon_{\text {true }}=\ln \left(1+\varepsilon_{\text {test }}\right)
$$

Newton-Raphson nonlinear analysis procedure was activated to obtain the solution after each displacement increment.

\section{EXPERIMENTAL RESULT}

The material properties of cold-formed steel obtained by ASTM A370-06 [13] are presented in Table II. The table shows the yield stress, the ultimate stress, the modulus of elasticity and the ultimate-to-yield stress ratio. The yield stress was used in calculating nominal strength of the bolted connection in this research. The shear resistance of the M5 Grade 8.8 highstrength steel bolts were tested. The results of the properties are shown in Table III. The load capacity and failure mode of shear connection tests are shown in Figure 6 to Figure 8. In the model, the loads were predicted by summing all $\mathrm{x}$-components of reaction force at support that were compared with the experimental data. The summarized results are shown in Table IV. Fifteen tests were conducted in this research. Specimens of shear connection were tested with different number of bolts such as, single bolt, double bolts and quadruple bolts. For each bolt configuration, 5 repeating tests were performed. The loaddeformation response was obtained from the real-time reading of two transducers that measured the load and elongation of connections as shown in Figure 9 to Figure 11. For FEA, the model was validated by comparing to the mode of failure and load capacity from the experiment investigation.

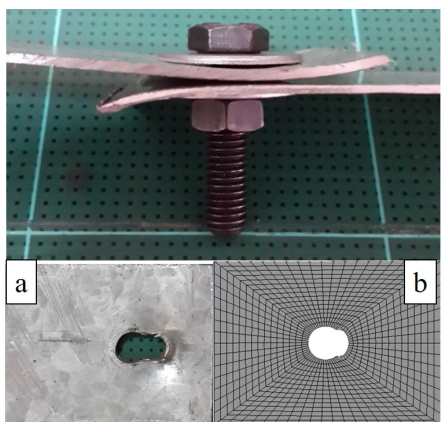

Fig. 6. The failure mode of single bolted connections: (a) deformation of specimen (b) deformation of specimen of FEA.

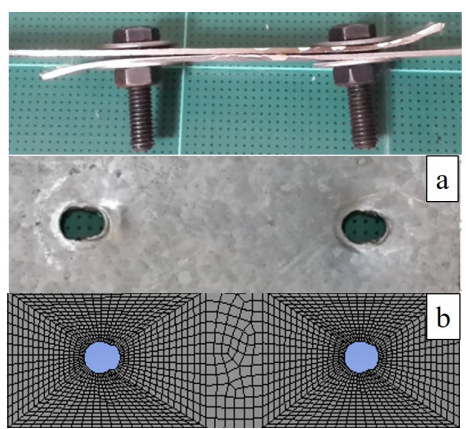

Fig. 7. The failure mode of double bolted connections: (a) deformation of specimen (b) deformation of specimen of FEA.

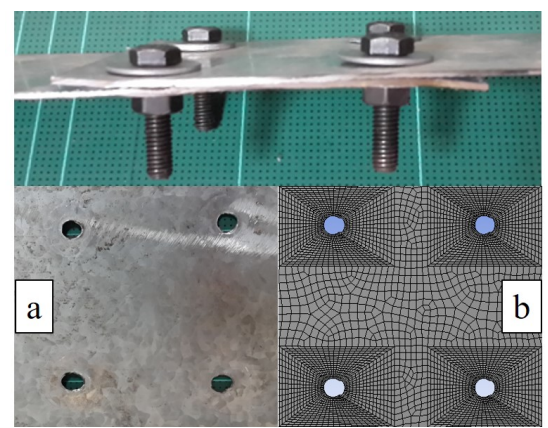

Fig. 8. The failure mode of quadruple bolted connections: (a) deformation of specimen (b) deformation of specimen of FEA.

TABLE II. MATERIAL PROPERTIES OF COLD-FORMED STEEL, G550-1T

\begin{tabular}{|c|c|c|c|c|c|c|c|c|}
\hline \multirow{2}{*}{ Item } & \multicolumn{5}{|c|}{ Test No. } & \multirow[b]{2}{*}{ Mean } & \multirow[b]{2}{*}{ SD. } & \multirow[b]{2}{*}{$\mathrm{COV}$} \\
\hline & $C T-1$ & $C T-2$ & $C T-3$ & $C T-4$ & $C T-5$ & & & \\
\hline$T,(\mathrm{~mm})$. & 1.045 & 1.045 & 1.044 & 1.045 & 1.045 & 1.04 & 0.0004 & 0.04 \\
\hline$W(\mathrm{~mm})$. & 12.64 & 12.65 & 12.59 & 12.58 & 12.52 & 12.59 & 0.0522 & 0.41 \\
\hline$F_{y}$ (MPa.) & 608.47 & 605.77 & 605.90 & 617.50 & 606.46 & 608.82 & 4.9715 & 0.81 \\
\hline$F_{u}(\mathrm{MPa})$. & 627.00 & 622.50 & 625.50 & 630.00 & 620.00 & 625.00 & 3.8890 & 0.62 \\
\hline$E$ (GPa.) & 213.51 & 213.49 & 213.49 & 213.58 & 213.58 & 213.53 & 44.1757 & 0.02 \\
\hline
\end{tabular}


TABLE III. MATERIAL PROPERTIES OF BOLTS

\begin{tabular}{|c|c|c|c|c|c|c|c|c|}
\hline & \multicolumn{5}{|c|}{ Test No. } & & & \\
\hline & $B T-1$ & $B T-2$ & $B T-3$ & $B T-4$ & $B T-5$ & Mean & SD. & $\mathrm{COV}$ \\
\hline Dia. (m.) & 4.93 & 4.97 & 4.97 & 4.97 & 4.94 & 4.95 & 0.019 & 0.393 \\
\hline$F_{y}(\mathrm{MPa})$. & 930.00 & 949.00 & 927.00 & 976.00 & 872.00 & 930.80 & 38.232 & 4.107 \\
\hline$F_{u}$ (MPa.) & 963 & 930 & 963 & 997 & 909 & 952.40 & 33.908 & 3.560 \\
\hline$E$ (GPa.) & 204.08 & 204.08 & 204.09 & 204.10 & 204.09 & 204.08 & 7.385 & 0.003 \\
\hline
\end{tabular}

TABLE IV. SUMMARIZATION OF THE TENSION CONNECTION RESULTS

\begin{tabular}{|c|c|c|c|c|}
\hline Test & Loading capacity, & Failure mode & $P_{n} / P_{n, A I S I}$ & $P_{n} / P_{n, F E A}$ \\
\hline \multicolumn{5}{|c|}{ Single bolt connection } \\
\hline S-1 & 12932.46 & $\mathrm{~B}$ & 1.42 & 0.82 \\
\hline S-2 & 13824.82 & $\mathrm{~B}$ & 1.52 & 0.88 \\
\hline S-3 & 13724.20 & $\mathrm{~B}$ & 1.50 & 0.87 \\
\hline S-4 & 12925.71 & $\mathrm{~B}$ & 1.42 & 0.82 \\
\hline S-5 & 14267.82 & $\mathrm{~B}$ & 1.56 & 0.91 \\
\hline FEM & 15749.25 & $\mathrm{~B}$ & & \\
\hline AISI & 9120 & $\mathrm{~B}$ & & \\
\hline Mean & & & 1.48 & 0.86 \\
\hline $\mathrm{SD}$ & & & 0.06 & 0.04 \\
\hline $\mathrm{COV}$ & & & 4.36 & 4.36 \\
\hline \multicolumn{5}{|c|}{ Double bolts connection } \\
\hline D-1 & 22194.70 & $\mathrm{~B}$ & 1.22 & 1.00 \\
\hline $\mathrm{D}-2$ & 20330.69 & $\mathrm{~B}$ & 1.11 & 0.92 \\
\hline D-3 & 22216.97 & $\mathrm{~B}$ & 1.22 & 1.00 \\
\hline D-4 & 21161.59 & $\mathrm{~B}$ & 1.16 & 0.95 \\
\hline $\mathrm{D}-5$ & 20846.29 & $\mathrm{~B}$ & 1.14 & 0.94 \\
\hline FEM & 22206.00 & $\mathrm{~B}+\mathrm{NS}$ & & \\
\hline AISI & 18240 & $\mathrm{~B}$ & & \\
\hline Mean & & & 1.17 & 0.96 \\
\hline $\mathrm{SD}$ & & & 0.05 & 0.04 \\
\hline $\mathrm{COV}$ & & & 3.91 & 3.91 \\
\hline \multicolumn{5}{|c|}{ Quadruple bolts connection } \\
\hline Q-1 & 39304.02 & $\mathrm{~B}$ & 1.08 & 0.86 \\
\hline Q-2 & 37306.07 & $\mathrm{~B}$ & 1.02 & 0.82 \\
\hline Q-3 & 35985.46 & $\mathrm{~B}$ & 0.99 & 0.79 \\
\hline Q-4 & 36273.24 & $\mathrm{~B}$ & 0.99 & 0.79 \\
\hline Q-1 & 38230.77 & $\mathrm{~B}$ & 1.05 & 0.84 \\
\hline FEM & 45759.00 & $\mathrm{~B}+\mathrm{NS}$ & & \\
\hline AISI & 36480 & $\mathrm{~B}$ & & \\
\hline Mean & & & 1.03 & 0.82 \\
\hline SD & & & 0.04 & 0.03 \\
\hline $\mathrm{COV}$ & & & 3.68 & 3.68 \\
\hline
\end{tabular}

\section{DISCUSSION}

The verified finite element model was to get insight into the failure mechanism of bolted connection under shear loading. The failure criteria depend on the deformation and strain distribution of connection. For all experiments, the deformation shape of typical specimens showed that the specimens were failed by bearing mode. In bearing mode, the load was transferred by friction and slippage until the bolt and the side of bolt hole came in contact. The bearing stresses were developed in contact regions. Finally, the applied load was increased until bearing failure occurred. In this research, the technique of bearing stress distribution was modified by using stress normalization analysis, namely the ratio of the in-plane VonMises stress contours normalized by the ultimate stress of the cold-formed steel material.

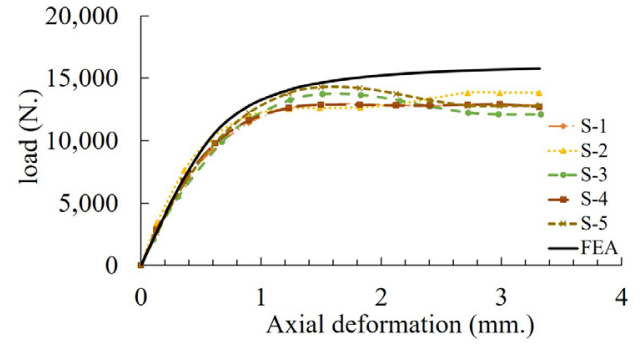

Fig. 9. Load-deformation curves of single bolted connection.

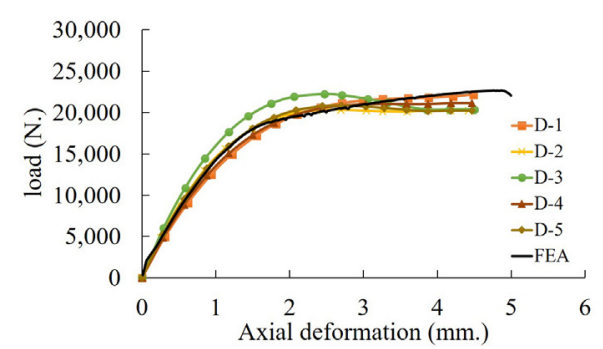

Fig. 10. Load-deformation curves of double bolted connection.

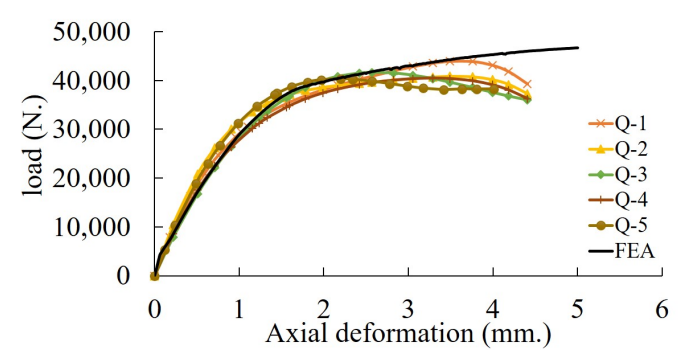

Fig. 11. Load-deformation curves of quadruple bolted connection.

For the bearing failure mode, it is expected that the strains at point $\mathrm{C}, \mathrm{D}$ and $\mathrm{E}$ are zero. For net section failure, it is assumed that strain at point $\mathrm{C}$ is equal to ultimate tension strain of cold-formed steel material as shown in Figure 12.

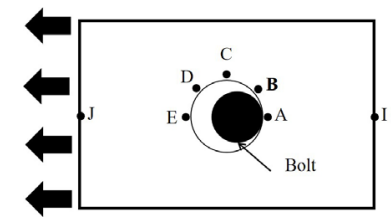

Fig. 12. Deformation of the plate with one hole.

The finite element models were verified against the experimental results in two steps. Firstly, the deformation 
results were validated by comparing the experimental results and finite element load-deformation curves. From the curves, it is confirmed that the load-deformation behavior from the FEA are in good correlation with the experiment results. Secondly, the ultimate strength capacities were compared with experiment results. The $P_{n} / P_{n . F E A}$ ratio in summarization of the shear connection results table shows that the models are in good agreement with the test results to predict ultimate strength capacities of bolted connection. In this study, the FEA was used to study the stress and strain behavior that produced the failure of the cold-formed steel. The stress-strain surrounding the bolt hole when the bearing failure occurs were shown in Figure 13 which presented the stress and strain distributions of the FEA with the stress contour normalized by the ultimate stress of cold-formed steel material.

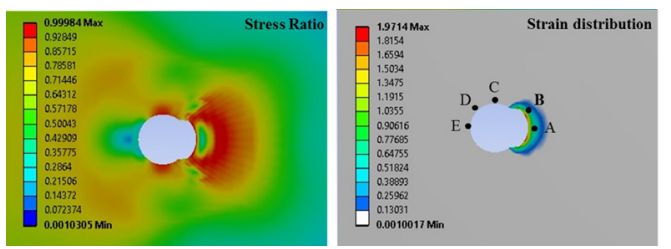

(a) Stress and strain distribution of single bolted connection

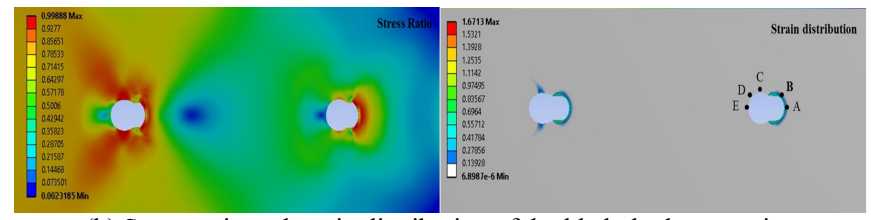

(b) Stress ratio and strain distribution of double bolted connection

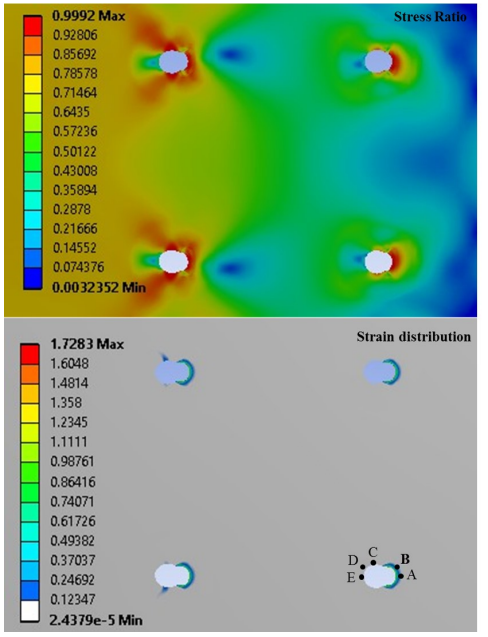

(c) Stress ratio and strain distribution of quadruple bolted connection

Fig. 13. Stress ratio and strain distribution of bolted connection at failure stage.

It should be noted that material yielding is obviously noticed in the vicinity of the bolt holes, representing stressstrain concentration under the bearing mode. However, net section failure mode was also observed in the double bolted and quadruple bolted connection models. The material model is one of the main influences to the accuracy in FEA results. The strength parameters, stress-strain relationship, ultimate stress and tensile stress were obtained in laboratory by conventional coupon tests. All of these parameters are reflected in the material model used in the FEA. Errors in the selection of material model and conversion parameters can effects the finite element model significantly. The local failure in cold-formed steel material also affects the accuracy in finite element modeling which is obviously observed under the large strain. In ANSYS, it is possible to model the local failure in steel materials using small elements with the global element midside nodes option to be predict the structural behavior.

The cold-formed steel bolted connection test capacities were compared with ultimate strength predicted by the AISI Specification (2012) as shown in Table IV. It shows the comparative results of ultimate strength between design standard, experimental results, strength ratio, mean value, standard deviation (SD) with the corresponding coefficient of variation $(\mathrm{COV})$. The nominal strength of bolted connection under shear was determined by one of four failure modes. However, the shearing of steel sheets, net section and shearing of bolt were not detected in the experiment results. Thus, the design equation related to the above failure modes were not mentioned in the study. Since the bearing mode is the main failure modes found in both FEA and experiment, the design equation for bearing capacity will be further studied in detail. The thickness in Table I and material properties in Table II were used to calculate the nominal strengths. Bearing of material in front of the bolt is illustrated in Figure $1 \mathrm{~b}$. The design bearing capacity per bolt for connections of the design standard is calculated by (2):

$$
P_{n}=n C m d t F_{u}
$$

where $n$ is the bolt number, $P_{n}$ is the nominal capacity between bolt and steel sheet, $t$ is thickness of steel sheet, $F_{u}$ is ultimate tensile strength of steel sheet, $C$ is bearing factor, $m$ is modification factor for type of bearing connection as shown in Table $\mathrm{V}$ and $d$ is the nominal bolt diameter as shown Table VI.

TABLE V. bEARING FACTOR. (AISI 2012)

\begin{tabular}{|c|c|c|}
\hline Thickness, $\boldsymbol{t}(\boldsymbol{m m})$. & $\boldsymbol{d} / \boldsymbol{t}$ & $\boldsymbol{C}$ \\
\hline \multirow{3}{*}{$0.61 \leq \mathrm{d} / \mathrm{t}<4.76$} & $\mathrm{~d} / \mathrm{t}<10$ & 3.0 \\
\cline { 2 - 3 } & $10 \leq \mathrm{d} / \mathrm{t} \geq 22$ & $4-0.1(\mathrm{~d} / \mathrm{t})$ \\
\cline { 2 - 3 } & $d / t>22$ & 1.8 \\
\hline
\end{tabular}

TABLE VI. MODIFICATION FACTOR FOR TYPE OF BEARING CONNECTION

\begin{tabular}{|c|l|c|}
\hline Case & \multicolumn{1}{|c|}{ Type of Bearing Connection } & $m$ \\
\hline I & $\begin{array}{l}\text { Single-shear and outside sheets of double-shear connection } \\
\text { with washers under both bolt head and nut }\end{array}$ & 1 \\
\hline II & $\begin{array}{l}\text { Single-shear and outside sheets of double-shear connection } \\
\text { without washers under both bolt head and nut or only one } \\
\text { washer }\end{array}$ & 0.75 \\
\hline III & $\begin{array}{l}\text { Inside sheet of double-shear connection with or without } \\
\text { washers }\end{array}$ & 1.33 \\
\hline
\end{tabular}

In statistical significance testing, the nominal strength predicted by AISI (2012) is correlation with the experiment 
results. As it is shown in Table IV, the calculated mean value $P_{n} / P_{n . \text { AISI }}$ ratio is $1.48,1.17$ and 1.03 for the single bolted, double bolted and quadruple bolted connections, respectively. It is shown that the bearing strength for the cold-formed steel bolted connection specimens using the AISI (2012) design standard is too conservative, which does not accurately reflect the actual connection strength. After the test results performed and compared to the AISI (2012) are higher than predictions when the ratio of $d / t$ was five.

The research revised the case I of modification factor for type of bearing connection using empirical method which is calculated as in (4):

$$
m_{\text {new }}=\frac{P_{n}}{C d t F_{u}}
$$

The new $m$ factor was shown in Table VII, the calculated value $P_{n} / P_{n \text { new }}$ ratio is $1.03,1.04$ and 1.00 for the single bolted, double bolted and quadruple bolted connections, respectively. These results are also plotted in Figure 11. The mathematical relation of the empirical method is presented in (5):

$$
m_{\text {new }}=1.3364 n^{-0.243}
$$

TABLE VII. PROPOSED MODIFICATION FACTOR FOR TYPE OF BEARING CONNECTION

\begin{tabular}{|c|c|c|c|}
\hline Type & Single bolt & Double bolts & Quadruple bolts \\
\hline $\begin{array}{c}\text { Average of } \\
\text { tests }(N)\end{array}$ & 13535 & 21350 & 37420 \\
\hline$m_{n e w}$ & 1.4 & 1.1 & 1.0 \\
\hline$P_{n, \mathrm{~m}_{n e v}}$ & 13125 & 20625 & 37500 \\
\hline$P_{n} / P_{n, \mathrm{~m}_{\text {ev }}}$ & 1.03 & 1.04 & 1.00 \\
\hline
\end{tabular}

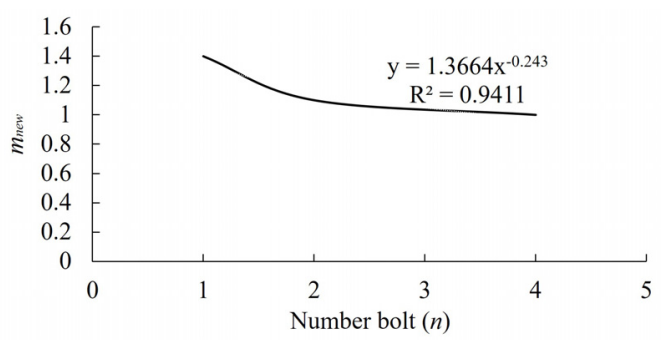

Fig. 14. New modification factor.

\section{CONCLUSION}

This paper presented an experimental investigation and FEA of cold-formed steel bolted connections with single and multiple bolts under shear loading. The specimens with various configurations were designed by varying the number of bolt as single shear, double shear and quadruple shear bolted connections. The geometric nonlinearity and material nonlinearity of finite element models have been implemented and verified against experimental results in the failure modes, load-deformation and ultimate capacity. Failure mode, loaddeformation and the ultimate capacity of finite element model were in good agreement with the experimental results. The experimental results and FEA were compared with the nominal strength predicted by AISI design standard. The comparison results show that current AISI (2012) design provisions for the cold-formed steel is too conservative, which provides the safe bearing resistances for the bolted connections with washers on oversized holes in single bolted, double bolted and quadruple bolted connections. However, this design standard is inconsistent to accurately predict the strength capacity of G550-1T bolted connection under the bearing failure modes. The new modification factor for type of bearing connection has a good agreement with the tested bearing strength of single shear connection.

\section{ACKNOWLEDGMENT}

The authors wish to acknowledge the Kasetsart University Research and Development Institute for providing financial funding support and BlueScope Lysaght (Thailand) Limited for material support.

\section{REFERENCES}

[1] R. Wei-Xin, F. Sheng-En, B. Young, "Finite-Element Simulation and Design of Cold-Formed Steel Channels Subjected to Web Crippling", Journal of Structural Engineering, Vol. 132, pp. 1967-1975, 2006

[2] American Iron and Steel Institute (AISI), Specification for the Design of Cold-Formed Steel Structural Members, American Iron and Steel Institute (AISI), 2012

[3] Standards Australia/Standards New Zealand, Cold-formed steel structures, AS/NZS 4600, Standards Australia/Standards New Zealand, 2001

[4] European Committee for Standardization, Eurocode 3.1996, Design of steel structures, Part 1.3 General rules, Supplementary rules for cold formed thin gauge members and sheeting, European Committee for Standardization, 1996

[5] C. A. Rogers, and G. J. Hancock, “ Bolted connection tests of thin G550 and G300 sheet steels", Journal of Structural Engineering Vol. 124, No.7, pp. 798-808, 1998

[6] C. A. Rogers, G. J. Hancock, "Bolted connection design for sheet steels less than $1.0 \mathrm{~mm}$ thick", Journal of Constructional Steel Research, Vol. 51, No. 2, pp. 123-146, 1999

[7] C. A. Rogers, G. J. Hancock, "Failure modes of bolted-sheet-steel connections loaded in shear", Journal of Structural Engineering, Vol. 126, No. 3, pp. 288-296, 2000

[8] C. Yu, K. Xu, I. Sheerah, "Bearing strength of cold-formed steel bolted connections using oversized holes without washers", Journal of Structural Engineering, Vol 137, No 1, pp. 156-159, 2010

[9] J. -S. Lim, T. -S. Kim, S. -H. Kim, "Ultimate strength of single shear bolted connections with cold-formed ferritic stainless steel", Journal of Zhejiang University SCIENCE A (Applied Physics \& Engineering), Vol. 14, No. 2, pp. 120-136, 2013

[10] C. Yancheng, B. Young, "Structural behavior of cold-formed stainless steel bolted connections", Thin-Walled Structures, Vol. 83, pp. 147-156, 2014

[11] C. Yu, M. X. Panyanouvong, "Bearing strength of cold-formed steel bolted connections with a gap", Thin-Walled Structures, Vol. 6, pp. 110115,2013

[12] AISI-S100, North American Specification for the Design of ColdFormed Steel Structural Members, 2015

[13] American Society for Testing and Materials, A370-07b Standard Test Methods and Definitions for Mechanical Testing of Steel Products, American Society for Testing and Materials, 2007

[14] American Society for Testing and Materials, A325M High Strength Bolts for Structural Steel Joints [Metric], American Society for Testing and Materials, 1994

[15] ANSYS Inc. ANSYS User's Manual. Revision 15. ANSYS Inc, 2015 